Document downloaded from:

http://hdl.handle.net/10251/83368

This paper must be cited as:

Sapena Bañó, A.; Riera Guasp, MV.; Puche Panadero, R.; Martínez Román, JA.; Pérez Cruz, J.; Pineda Sánchez, M. (2016). Harmonic Order Tracking Analysis: A Speed-

Sensorless Method for Condition Monitoring of Wound Rotor Induction Generators. IEEE Transactions on Industry Applications. 52(6):4719-4729. doi:10.1109/TIA.2016.2597134.

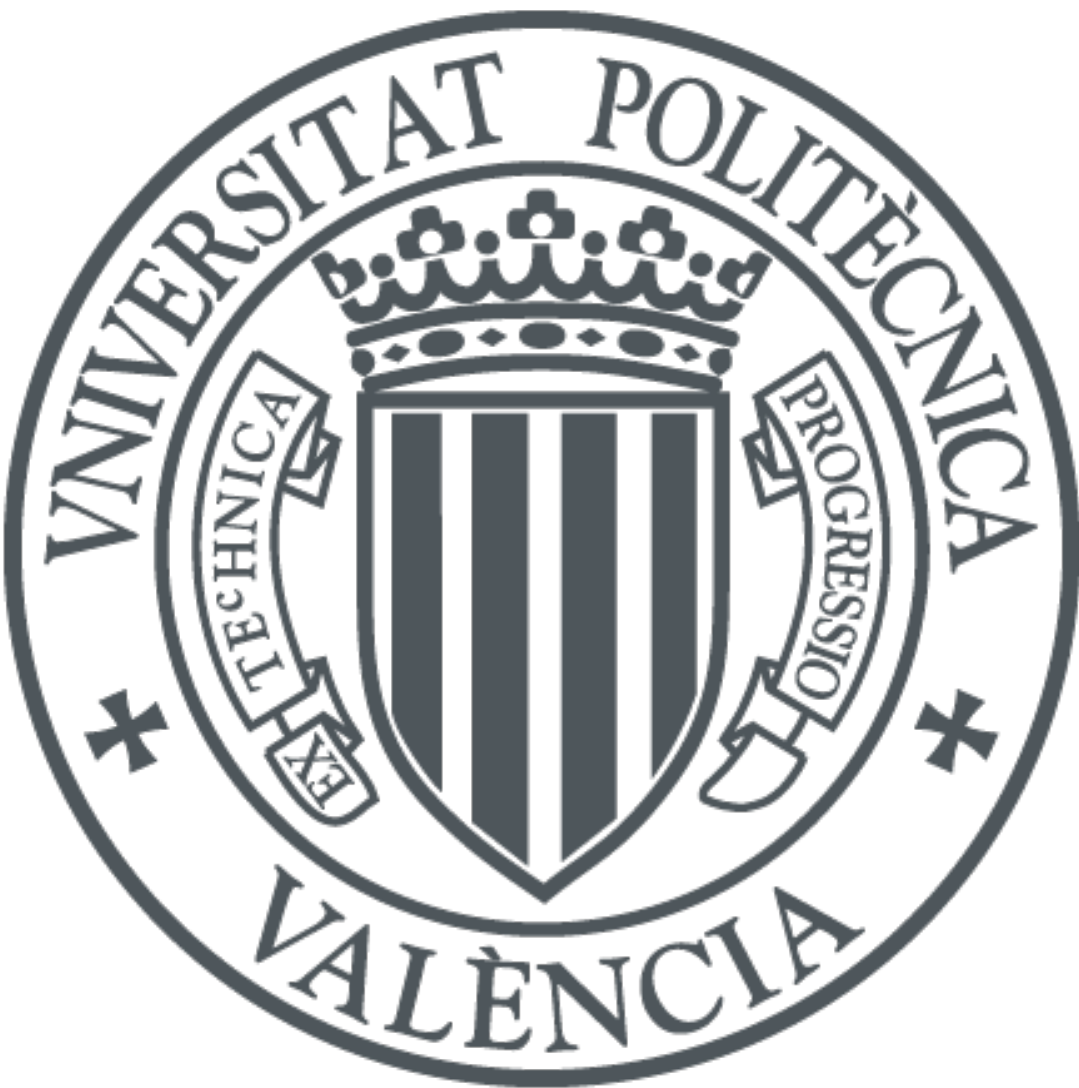

The final publication is available at

http://doi.org/10.1109/TIA.2016.2597134

Copyright Institute of Electrical and Electronics Engineers (IEEE)

Additional Information

"(c) 2016 IEEE. Personal use of this material is permitted. Permission from IEEE must be obtained for all other users, including reprinting/ republishing this material for advertising or promotional purposes, creating new collective works for resale or redistribution to servers or lists, or reuse of any copyrighted components of this work in other works." 


\title{
Harmonic Order Tracking Analysis: A Speed-Sensorless Method for Condition Monitoring of Wound Rotor Induction Generators
}

\author{
A. Sapena-Baño, M. Riera-Guasp, Senior Member, IEEE, R. Puche-Panadero, Member, IEEE, J. Martinez-Roman, \\ J. Perez-Cruz, Member, IEEE, and M. Pineda-Sanchez, Member, IEEE
}

\begin{abstract}
This paper introduces a speed-sensorless method for detecting rotor asymmetries in wound rotor induction machines working under non-stationary conditions. The method is based on the time-frequency analysis of rotor currents and on a subsequent transformation which leads to the following goals: unlike conventional spectrograms, it enables to show the diagnostic results as a simple graph, similar to a Fourier spectrum, but where the fault components are placed always at the same positions, regardless the working conditions of the machine; moreover, it enables to assess the machine condition through a very small set of parameters. These characteristics facilitates the understanding and processing of the diagnostic results and thus, help to design improved monitoring and predictive maintenance systems. Also these features make the proposed method very suitable for condition monitoring of wind power generators, because it fits well with the usual non-stationary working conditions of wind turbines, and makes feasible the transmission of significant diagnostic information to the remote monitoring center, using standard data transmission systems. Simulation results and experimental tests, carried out on a $5 \mathrm{~kW}$ laboratory rig, show the validity of the proposed method and illustrate its advantages regarding previously developed diagnostic methods under non-stationary conditions.
\end{abstract}

Index Terms-Condition monitoring, extended Park's Vector, fault diagnosis, Fourier transforms, Gabor transform, harmonic order tracking analysis, motor-current signature analysis, nonstationary working conditions, rotor asymmetries, signal processing, time-frequency distributions, wound rotor induction machines.

\section{INTRODUCTION}

$\mathbf{R}$ ELIABILITY is a key issue for optimal exploitation of industrial plants, where unscheduled interruptions of processes can produce huge economic losses and safety issues. During last years, the topics related to the reliability of electrical machines have generated a huge research activity. Particularly, the research on diagnostic techniques for wound rotor induction machines (WRIMs) have gained relevance, due to the massive implantation of this kind of machines in wind power plants. The development of solutions for reducing maintenance, increasing the reliability, and extending the lifetime of offshore wind turbines was identified as a specific

This work was supported by the Spanish "Ministerio de Economía y Competitividad" in the framework of the "Programa Estatal de Investigación, Desarrollo e Innovación Orientada a los Retos de la Sociedad" (project reference DPI2014-60881-R).

Authors are with the Institute for Energy Engineering, Universitat Politècnica de València, Camino de Vera s/n, 46022, Valencia, Spain. challenge inside the Horizon 2020 work programme 20162017 of the European Union [1]. Maximizing the reliability involves improving condition monitoring and fault detection systems. Wind turbines components and the wound rotor induction generators (WRIGs) are exposed to different sort of failures [2], [3]. Traditionally, wind turbine condition monitoring systems have used temperature sensors, oil analysis and vibration analysis to detect faults in the global system [3], [4]. Among these, vibration analysis has emerged as the main method to assess the condition of wind turbines components [5]-[7], despite of its drawbacks: several vibration sensors must be installed, which, besides being expensive, can affect the reliability of the system, due to potential malfunctions in the accelerometers. In fact, the ideal condition monitoring system is supposed to monitor all the components, using a minimum number of sensors and data for obtaining a reliable fault diagnosis [3].

Following this trend, fault diagnosis of wind turbines based on analysis of currents is being considered as a promising methodology because it would take the benefit of the experience in diagnosing electrical motors using motor current signature analysis (MCSA) techniques. Diagnosis through MCSA is a dynamic field of research, which has experienced a great development in recent decades, and has resulted in a significant variety of diagnostic techniques [8]-[18]. A general overview of MCSA techniques can be found in [8], [9].

Conventional MCSA techniques are based on the fast Fourier transform (FFT), and are only suitable for machines working in steady state. In this field a huge number of works have been developed for improving the reliability of the fault diagnosis, and for solving the practical issues associated with the industrial application of these techniques. Nevertheless there are still two main drawbacks unsolved, related with their practical implementation:

- MCSA techniques are valid only for steady state regime.

- They require very accurate speed measurement, since the theoretical frequencies of fault components depend on slip or rotor speed. In most cases this requires installing speed sensors, which is problematic and in some cases, almost impossible.

To solve these problems, recent fault diagnosis techniques have focused on the analysis of the stator current during the direct on-line start-up through time-frequency $(t-f)$ signal analysis, since: 
- Time-frequency signal analysis tools allow to extract the different frequency components along the start-up transient [13], [14], [16].

- The start-up is an electromechanical transient in which the slip evolution is well-known (from 1 to near 0 ). Hence the speed measurement is not needed.

In the field of diagnosis under transient conditions, a wide variety of techniques based on $t-f$ domain analysis have been also introduced, as in [13], where the short time Fourier transform with an optimized Gabor windows is introduced. In [14]-[16] the discrete wavelet transform (DWT) and the continuous wavelet transform (CWT) are used, for making visible the characteristic patterns of the sideband components. In [17] the $t-f$ analysis is performed through the WignerVille distribution, whereas [18] develops an approach based on The Hilbert-Huang transform (HHT)). Usually, $t-f$ based techniques apply some type of demodulation to the currents signal, before perform the $t-f$ analysis, what improves the readability of the spectrograms. Signals demodulation can be performed through several techniques as the extended Park's vector approach (EPVA) [10] or stator-current space-vector magnitude spectral analysis [11], or the Hilbert transform (HT) [12].

These significant advances in MCSA have suggested the feasibility to apply similar techniques to fault diagnosis in wind turbines [3], [19]-[23]. However, the aforementioned condition monitoring methods cannot be directly applied to wind generators. Wind turbines neither work under strictly steady state regime, nor are subjected to transients with large variations of slip, as in the case of start-up transients. Hence, the previous knowledge in condition monitoring through the currents analysis must be adapted to a new scenario, where the machine works under random non-stationary conditions. Nowadays, a new research field is emerging, focused on adapting the MCSA techniques to such working conditions, in which two trends prevail. On the one hand, as the signals are quasi-stationary, some researches apply the same methods than in steady state [3], [24], but this analysis introduces new errors and, therefore, decreases the reliability of the diagnosis. On the other hand, the second trend is to apply techniques specifically designed for non-stationary functioning as [20], which proposes an approach for diagnosing rotor faults in WRIM based on the use of wavelet analysis improved by a preprocessing of the rotor-voltage commands under timevarying conditions or [25] which compares several timefrequency representations for broken rotor bars fault detection in a squirrel-cage wind turbine generators. Also, recent works have proposed to analyze the rotor current instead of the stator current, whereby certain advantages are achieved, as in [19][22], for detecting both rotor and stator asymmetries in a WRIM. In [21] the fault diagnosis is performed under steadystate, through the spectral analysis of the modulus of the Park's vector of the rotor current, and of the modulating signals generated by the drive control. In [22] a load independent method for detecting stator windings asymmetries based on rotor current measurement is introduced. In [19], [20], the rotor currents under non-stationary regimes involving speed variations are analyzed by decomposing the signals in different frequency bands through the DWT. Nevertheless, all these approaches share a common drawback: They require speed measurement to identify the fault components in the spectrum or to know in which approximation and detail bands of the DWT decomposition the fault components should appear, or to forecast the fault components trajectories in the $t-f$ plane. Besides, the fault components have not pre-defined pat-terns when load or feeding conditions vary randomly. Hence, the use of these techniques require additional calculations to characterize the fault components signatures. And this must be done for every test. These facts make difficult the implementation of these techniques in industrial applications (such as wind turbines condition monitoring), and also in automatic recognition systems and classifiers. Furthermore, the historical management of the condition of the machine implies large memory requirements, especially in transient analysis, because it is necessary to store the $t-f$ distributions (three dimensional) or the DWT results, as in [20]. The methodology proposed in this paper is aimed to solving these problems. This paper is an enhanced version of a previous conference paper [23]. It is based on a new transform, the harmonic order tracking analysis (HOTA), which was introduced in [26]. The HOTA method, as was developed in [26], is a technique for improving the fault diagnosis reliability; it is based on the conventional Fourier spectrum of the stator current of induction machines (IMs) working in steady state regimes. Unlike this work, in this paper the HOTA methodology is improved to perform the diagnosis of faults in WRIM under non-stationary working conditions. The proposed approach is based on a new transform, which is applied to the spectrogram resulting from the $t-f$ analysis of the module of the rotor currents Park's vector. The achievements of the proposed method are:

- It does not requires any speed measurement.

- The results are presented using a plot similar to the Fourier spectrum, but with the fault components located always at the same positions, regardless the working conditions and the type of non-stationary functioning.

- The machine condition can be characterized by a very reduced set of parameters, thus reducing the memory requirements to set up an historical analysis of the machine condition, and facilitating the data transmission to remote diagnostic centers. This feature makes it very suitable for automatic recognition systems and classifiers, and also, is helpful for the implementation of the method in industrial environments, since it enables reliable diagnostics even by low qualified maintenance staff.

In this paper this new methodology is theoretically demonstrated for detecting rotor asymmetries, but it can be easily extended to detect other types of faults, such as stator asymmetries, eccentricity and damaged bearings.

This paper is structured as follows: in Section II the physical analysis of the rotor faults and the proposed signal processing tool are depicted. Subsequently, in Section III the theoretical development of the proposed methodology as well as its practical implementation are explained in detail. A simulated 
case of study is also developed for illustrating the method. Section IV shows the experimental validation of the method. In Section $\mathrm{V}$ the results of the application of the approach to healthy and faulthy machines are compared in detail. Finally in Section VI the conclusions are summarized.

\section{THEORETICAL BACKGROUND}

In healthy rotating electrical machines, stator and rotor currents are symmetrical and generate a rotating magnetic field at frequency $f$ in the stator reference frame, or $s f$ in the rotor reference frame, where $f$ is the frequency of the power supply as $s$ is the slip. Nevertheless WRIMs used in wind turbines are subject to mechanical and electromagnetic stresses, which may result in the appearance of imbalances caused by faults such as inter-turn short circuits, eccentricities, high-contact resistance connections, bearing damages, etc. Besides, it is well known that each fault induces or increases a family of harmonic components in the stator and rotor currents whose frequencies have been theoretically deduced, as can be seen in Table I, where $f_{r}$ is the rotational speed frequency and $N_{b}$ is the number of balls of the bearings (being these expressions only valid for 6 $\leq N_{b} \leq 12$ ).

TABLE I

FREQUENCIES OF THE HARMONIC COMPONENTS GENERATED IN THE STATOR AND ROTOR CURRENTS BY DIFFERENT TYPES OF FAULTS IN INDUCTION MACHINES

\begin{tabular}{cccc}
\hline $\begin{array}{c}\text { Measured } \\
\text { Current }\end{array}$ & Fault & Frequency & Cites \\
\hline Stator & Rotor asymmetry & $f_{b b}=(1 \pm 2 k s) f(k=1,2,3 .)$. & [27] \\
Stator & Mixed eccentricity & $f_{\text {ecc }}=f \pm k f_{r}(k=1,2,3 .)$. & {$[28],[29]$} \\
Stator & Bearing inner race & $f_{\text {in }}=f \pm k 0.4 N_{b} f_{r}(k=1,2,3 .)$. & {$[30]$} \\
Stator & Bearing outer race & $f_{\text {out }}=f \pm k 0.6 N_{b} f_{r}(k=1,2,3 .)$. & {$[30]$} \\
Rotor & Stator asymmetry & $f_{k s a}=(2 k \pm s) f(k=1,2,3 .)$. & {$[21]$} \\
Rotor & Rotor asymmetry & $f_{k r a}= \pm k s f(k=1,3,5 .)$. & {$[21]$} \\
\hline
\end{tabular}

Under stationary regime, these components can be detected through a frequency domain analysis technique, as the FFT. Nevertheless, when the working conditions are non-stationary, these characteristic harmonics become components whose frequency and amplitude vary along the time. Under these conditions, the fault components cannot be detected through the conventional FFT; $t-f$ techniques based on linear transforms, such as the short time Fourier transform (STFT), the CWT, and the Gabor transform, or quadratic transforms, such as the Wigner-Ville distribution (WVD), are needed for extracting the fault components information. Usually, the result of the $t-f$ analysis is summarized as a spectrogram (that is, as a plot of the signal energy distribution along the $t-f$ domain). In this work, the Gabor transform, as used in [13], has been selected for obtaining high resolution spectrograms, which clearly reveal the existence of the fault components. Nevertheless, under non-stationary conditions, where load, supply conditions and speed may vary randomly, there are no predefined patterns for the fault components, and thus, high resolution spectrograms are not sufficient for a reliable fault diagnosis. This paper introduces a method for processing the $t$ $-f$ information of the rotor current given by the $t-f$ analysis. As a result, the information corresponding to the machine condition is displayed in a simple and clear diagram where the failure components appear located always at the same position, irrespective of the working conditions.

Basically the method consist in applying changes of variable to the frequency scale of the spectrograms. These changes of variable are specific for every kind of fault and are based on the expressions of the frequencies of the fault components families, given in Table I. For the case of the diagnostic of rotor asymmetries through measurement of rotor currents -that will be developed in this paper- the variable changes are based on the expression of the last row of Table I. This expression, as it was introduced in [21] is not very suitable for being used in the code of the diagnostic algorithm, since every $k \in \mathbb{N}$ designates two different components. Thus, it is more convenient to use the equivalent expression (1), since for every $k \in \mathbb{Z}$, it unambiguously designates a unique fault component.

$$
f_{k r a}=(1+2 k) s f k=0, \pm 1, \pm 2, \pm 3 \ldots(k \in \mathbb{Z})(1)
$$

\section{PRoposed Methodology}

To introduce the proposed methodology of faults diagnosis under non-stationary conditions, it has been decomposed into five conceptual tasks, shown in the block diagram of Fig. 1, that will be explained in detail in this section.

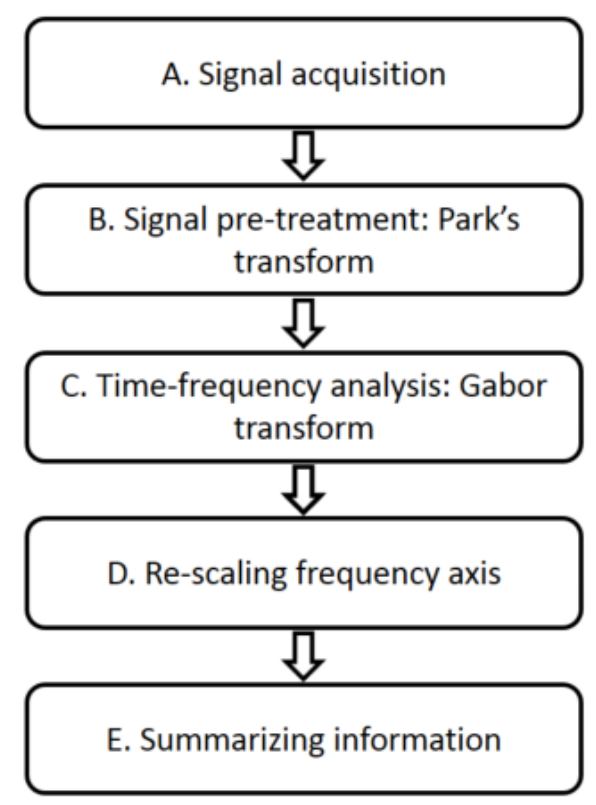

Fig. 1. Block diagram of the proposed technique to compute the harmonic order tracking analysis under time-varying conditions.

Additionally, for improving the understanding of the method, an example of application based on Matlab simulation is developed at the same time that the theoretical explanation. 
The simulation has been performed using an analytical threephase model of WRIM implemented in Matlab-Simulink (from the SimPowerSystems toolbox, more precisely the preset model 16). Table II shows the parameters of the sim-ulated machine that were used in the model. As it can be seen in Fig. 2 , for simulating the fault, a resistance $R_{\text {asym }}=0.09 \Omega$ (equivalent rotor referred to stator resistance $R_{\text {asym }}^{\prime}=0.27 \Omega$ ) is connected in series with one of the rotor phases. This configuration simulates an high-contact resistance connection fault in actual machines [31], [32]. Applying a variable wind speed to the model, a rotor speed evolution shown in Fig. 3 is obtained.

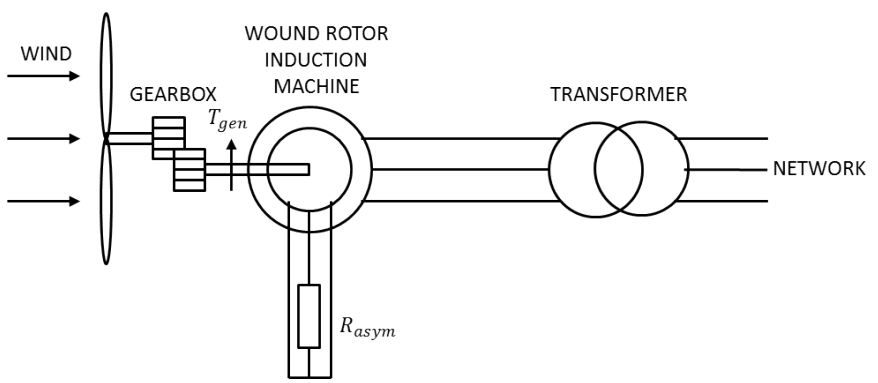

Fig. 2. Rotor asymmetry simulation setup scheme.

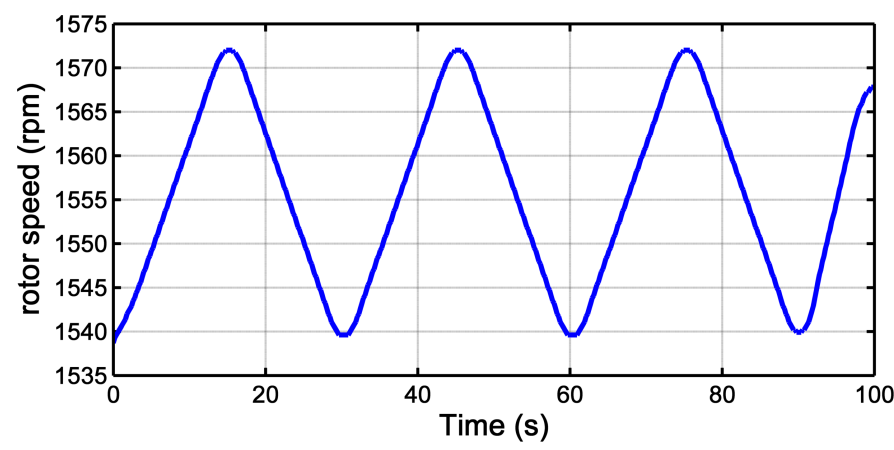

Fig. 3. Rotor speed evolution applied to the simulated machine.

\section{A. Signal acquisition}

This step consists on acquiring the signals needed for calculating the rotor current Park's vector. For this purpose, rotor currents, $i_{a r}, i_{b r}, i_{c r}$, must be measured (Fig. 4).

TABLE II

PARAMETERS OF THE SIMULATED MACHINE (WRIM) USED IN THE MODEL

\begin{tabular}{cccc}
\hline Nominal Power $($ VA) & 8800 & Voltage & $230 \mathrm{~V}$ \\
\hline Stator Resistance & \multicolumn{3}{c}{ Rotor Resistance } \\
$R_{s}$ & $0.345 \Omega$ & $R_{r}^{\prime}$ & $1.292 \Omega$ \\
\hline $\begin{array}{c}L l_{s} \\
\text { Stator Inductance }\end{array}$ & $6.3 \mathrm{mH}$ & Rotor Inductance \\
\hline $\begin{array}{c}\text { Mutual Inductance or } \\
\text { Magnetizing Inductance }\end{array}$ & $92.9 \mathrm{mH}$ & Pole Pairs & 2 \\
\hline Inertia factor & $0.2 \mathrm{~kg} \cdot \mathrm{m}^{2}$ & $R_{\text {asym }}^{\prime}$ & $0.27 \Omega$ \\
\hline
\end{tabular}
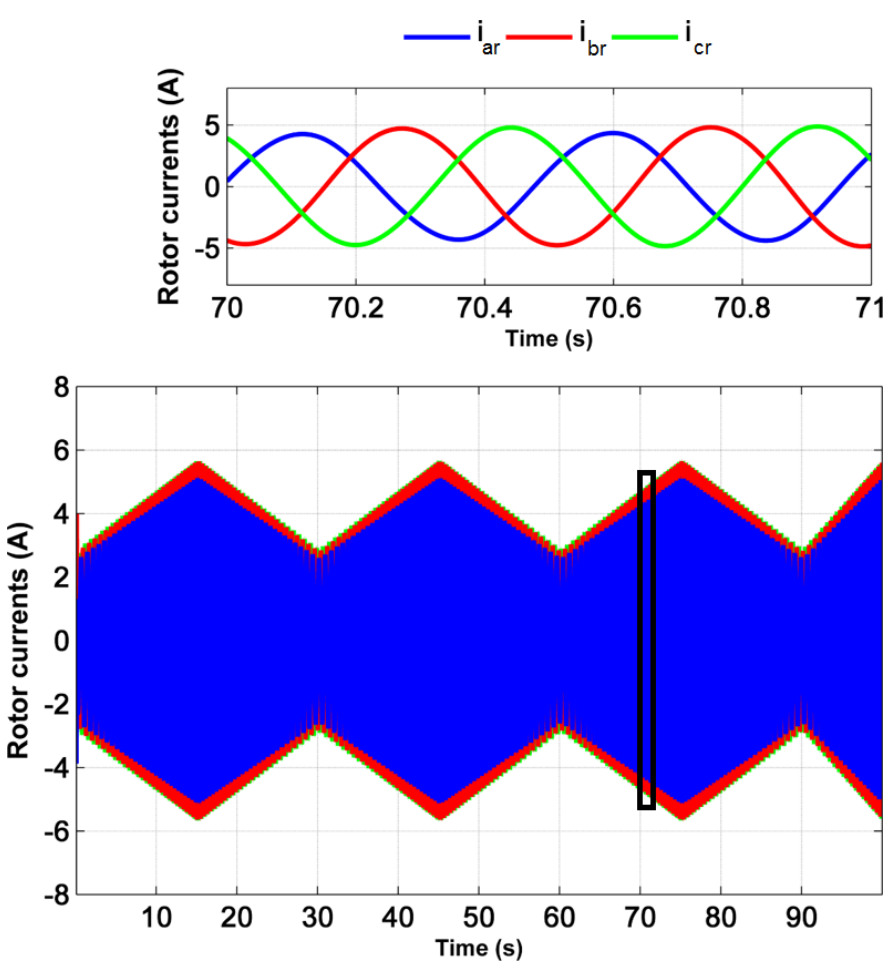

Fig. 4. Simulated rotor currents (bottom) and one second expansion (top).

\section{B. Signal pre-treatment: Park's transform}

The Park's transform was introduced in 1929 [33] as a tool to facilitate the analysis of the three-phase machines func-tioning and also, the understanding of its internal phenomena. The application of the Park's transform to a set of three phase values of a certain physical quantity (voltage, current, flux linkage ...) gives a vector (Park's vector) defined in the time domain by its $d-q$ components. In this work, the Park's transform is applied to the rotor phase currents $\left(i_{a r}(t), i_{b r}(t)\right.$, $\left.i_{c r}(t)\right)$ of a WRIG, obtaining the rotor current Park's vector components $i_{d r}(t)(2), i_{q r}(t)$ (3) and finally, the rotor current Park's vector (4),

$$
\begin{gathered}
i_{d r}(t)=\sqrt{\frac{2}{3}} i_{a r}(t)-\frac{1}{\sqrt{6}} i_{b r}(t)-\frac{1}{\sqrt{6}} i_{c r}(t), \\
i_{q r}(t)=\frac{1}{\sqrt{2}} i_{b r}(t)-\frac{1}{\sqrt{2}} i_{c r}(t), \\
\vec{i}_{r}(t)=i_{d r}(t)+j \cdot i_{q r}(t) .
\end{gathered}
$$

Usually, the WRIGs use a stator flux oriented control system for enabling decoupled active and reactive power control. For this purpose, the control system of the drive calculates the $i_{d r}, i_{q r}$ components of the current space vector (which for the calculations that will be performed, are equivalent to the Park's vector components [33]). In these cases, if the $i_{d r}, i_{q r}$ signals are available, the Park's vector can be built applying (4) and the diagnostic system do not need to sample three rotor phase currents.

At the beginning of the 1990s, fault diagnostic techniques based on representation of the evolution of the stator current 
Park's vector over time, were developed. Conceptually, these techniques are based on comparing the Park's vector trajectory, obtained from the sampled phase-currents, with that of the ideal healthy machine, which is a circumference [34]. Later, the concept of Extended Park's vector approach was introduced [10]. This technique is based on the analysis of the modulus of the Park's vector, since as stated in [35], under fault conditions, "the current Park's Vector modulus will contain a dominant DC level related with the fundamental component amplitude and an AC level, whose existence is directly related with the asymmetries either in the motor or in the supply voltage system". The EPVA acts as a demodu-lation tool, which facilitates the extraction of the fault related components at their true frequency, instead of combined with the frequency of the fundamental component, as happens when the sideband components are extracted from the phase currents through the conventional FFT. Initially the EPVA was applied to steady state analysis, through the Fourier analysis of the current Park's vector module [10], [35]; lately, it was successfully applied under transient conditions, combined with signal analysis techniques in the $t-f$ domain as the discrete wavelet transform [36], [37]. In this paper the EPVA is applied to the rotor currents of a WRIG working under random non-stationary load conditions. The Gabor transform is used as $t-f$ analysis technique, for extracting the faults components from the Park's vector module, as it is explained in the next section.

\section{Time-Frequency analysis: Gabor transform}

Once the Park's vector of the rotor currents is built, a $t-f$ analysis of its amplitude is carried out. In this work, the Gabor transform as proposed in [13] is used for this purpose. $t-f$ analysis basically consists on depict how the signal energy spreads among different frequencies at every time. A spectrogram is a plot of the signal energy spreading along time. Fig. 5 explains the conceptual way to build the spectrogram of a sampled signal.

Actually the signal energy is calculated on the nodes of a lattice on the $t-f$ plane, whose reticules are sized $T(s) \times \Omega$ $(\mathrm{Hz})$. The energy $E_{m n}$ at the node $\left(t_{n}, f_{m}\right)$, -where $t_{n}=n T$, $f_{m}=m \Omega, m, n \in \mathbb{N}$ - is calculated as the squared module of the inner product of the analysed signal $i_{r}(t)$ and a $t-f$ atom $g_{m n}(t)$, which is a function defined in $\mathbb{C}$ whose energy is concentrated in a short time interval around time $t_{n}$ and inside a narrow frequency band centred in $f_{m}$, and where $i_{r}(t)$ is the amplitude of the rotor Park's vector and $(*)$ denotes the complex conjugate,

$$
\begin{gathered}
E_{m n}=\left|c_{m n}\right|^{2}, \\
c_{m n}=\left\langle i_{r}, g_{m n}\right\rangle=\sum^{k} i_{r k} \cdot g_{m n k}^{*} .
\end{gathered}
$$

If the analysed signal includes relevant harmonic components at frequencies near to $f_{m}$, at time $t_{n}$, the value of the coefficient $c_{m n}$ will be high. Conversely if the signal does not contain components with frequency near $f_{m}$ at time $t_{n}$ or these component have a low value, the $c_{m n}$ coefficient

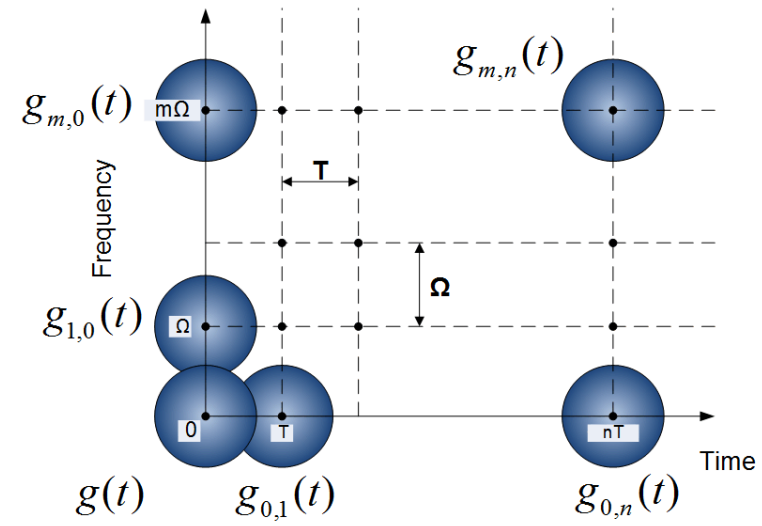

Fig. 5. Extraction of signal components through inner products of the signal with time-frequency atoms, whose energy is concentrated around the nodes of the lattice built in the $t-f$ plane.

will be zero or small. Actually, the atom $g_{m n(t)}$ perform as a narrow bandpass filter with a central frequency $f_{m}$ [13] which is applied to the signal during a short time interval around time $t_{n}$.

The atoms $g_{m n}(t)$ are a family of functions derived through translation in time and modulation in frequency from a basic function $g(t)$ designated as the synthetic window and they can be written as:

$$
g_{m, n}(t)=g(t-n T) e^{j 2 \pi m \Omega t} \quad m, n \in \mathbb{N} .
$$

The analysis performed in this work uses the Gaussian function (8) as synthetic window, since as stated [13] this function enables for the maximum energy concentration. The Gaussian function is defined by:

$$
g(t)=\left(\frac{\alpha}{\pi}\right)^{1 / 4} e^{-\alpha t^{2} / 2} .
$$

For obtaining a high quality spectrogram it is crucial a suitable selection of the lattice parameters $T$ and $\Omega$ as well as of the Gaussian function parameter $\alpha$.

Regarding the lattice parameters, as [13] points out, as T, $\Omega$ get smaller the readability of the spectrogram improves. But from a practical point of view, the discretization process imposes minimum values for the time and frequency steps $\Delta \mathrm{t}$, $\Delta f_{c}$ [13]. If the current signal $i_{r}(t)$ is sampled during time $T_{S}$ at a frequency $F_{S}$, obtaining $N=T_{S} \cdot F_{S}$ samples, then,

$$
\begin{aligned}
& \Delta t=\frac{T_{S}}{N}=\frac{T_{S}}{T_{S} \cdot F_{S}}=\frac{1}{F_{S}}, \\
& \Delta f=\frac{F_{S}}{N}=\frac{F_{S}}{T_{S} \cdot F_{S}}=\frac{1}{T_{S}} .
\end{aligned}
$$

In this work all the spectrograms have been calculated by setting the lattice parameters to the minimum achievable values; thus taking into account the values used for the sampling time $\left(T_{S}=100 \mathrm{~s}\right)$ and sampling frequency $\left(F_{S}=10,000 \mathrm{~s}^{-1}\right)$, the calculated lattice parameters are:

$$
T=\Delta t=\frac{1}{10000}=0.0001 s
$$




$$
\Omega=\Delta f=\frac{1}{100}=0.01 \mathrm{~Hz} .
$$

On the other hand, regarding the Gaussian function parameter $\alpha$, the optimization criteria proposed in [13] will be adopted. There, it is justified that to achieve a good discernibility of the fault components in the spectrogram, the value of $\alpha$ must be set according to the slope of the fault component in the $t-f$ plane and can be approximated by:

$$
\alpha \approx 2 \pi \frac{d f_{f}}{d t} \approx 2 \pi \frac{\Delta f_{f}}{\Delta t}=2 \pi \frac{(1+2 k) f \Delta s}{\Delta t} .
$$

Considering the main fault component $(\mathrm{k}=-1)$ and using the rotor speed as variable, instead of the slip, (13) becomes:

$$
\alpha \approx \frac{2 \pi f}{n_{s}} \cdot \frac{\Delta n}{\Delta t}=\frac{\pi p}{30} \cdot \frac{\Delta n}{\Delta t} .
$$

The ratio $\Delta n / \Delta t$ is estimated from Fig. 3, which plots the speed evolution that was imposed during the simulations:

$$
\frac{\Delta n}{\Delta t}=\frac{1572-1540}{15-0}=2.1 \mathrm{rpm} / \mathrm{s} .
$$

Substituting (15) in (14) and taking into account that number of pole pairs of the simulated machine is $\mathrm{p}=2$, a value $\alpha=0.44$ is obtained, and the synthetic window is finally given by

$$
g(t)=\left(\frac{0.44}{\pi}\right)^{1 / 4} e^{-0.44 t^{2} / 2} .
$$

Figs. 6(a) and 6(b) show the 3D and 2D spectrograms of the amplitude of the Park's vector obtained through this methodology for the simulated faulty machine.

\section{Re-scaling frequency axis}

Figs. 6(a) and 6(b) show the time evolution of the rotor current components. To determine if they are due to a failure, it would be necessary, for every time, to calculate the theoretical frequencies of the fault components. This would be carried out by considering the equations of failure (see Table I), the fundamental frequency and the measured speed (Fig. 3). Later, it would be necessary to check if theoretical components match those of the experimental distribution. Although this process can be automatically performed, it imposes certain computational cost. In steady state the process is identical but only a single operating point is calculated.

The aim of this work is to obtain the evolution of the fault related components without speed measurement. Besides, this subsection introduces a change of variable that rescales the frequency axis of the spectrogram, in such a way that the fault components appear as single horizontal lines, improving the diagnosis by offering a fast and visual tool to know the condition of the machine. As can be seen in Table. I, there is a common parameter in any failure equation which is independent of the working conditions and of the type of fault. This is the dimensionless $k$ parameter that indicates the harmonic order of the fault components. Hence, if the spectral analysis is performed using a variable based on this harmonic order, then the fault components always will appear in the same position on the horizontal axis, regardless of the working conditions, the frequency supply, the speed and the type of fault, improving the evaluation of the results and achieving a more efficient and reliable representation of the machine condition.

In the case of rotor asymmetries, the faults generate harmonic components in the rotor currents at frequencies given by (1). Hence, in the $t-f$ distribution, for every time $t_{j}$, the frequency axis is re-scaled according to

$$
f_{j}^{T}=\frac{f_{j}-f_{j}^{r}}{2 f_{j}^{r}},
$$

where $f_{j}^{T}$ is the transformed frequency of $f_{j}$ and $f_{j}^{r}$ is the rotor fundamental frequency at time $t_{j}\left(f_{j}^{r}=s_{j} f_{j}\right)$. It is noticeable that the mathematical expression of the transformed frequency (right term of (17)) is simply obtained by solving (1) in k. It is also remarkable that $f_{j}^{r}$ is obtained as the frequency of the component of higher energy at time $t_{j}$ in the spectrogram, and speed is not used for perform this selection. The interpretation of (17) is immediate: for a given time $t_{j}$ a linear transform is applied to the scale of frequencies of the Gabor spectrogram; this transform $\left(f_{j}^{T}\right)$ consists on shifting the frequency $\left(f_{j}\right)$ a frequency equal to the fundamental frequency at this time $\left(f_{j}^{r}=s f\right)$ and normalizing by $\left(2 f_{j}^{r}=2 s_{j} f_{j}\right)$ obtaining the result in p.u. of the fundamental frequency. Hence, the transformed frequency of a fault component of order $k$ is (18)

$$
f_{k r a, j}^{T}=\frac{(1+2 k) s_{j} f_{j}-s_{j} f_{j}}{2 s_{j} f_{j}}=k \quad k= \pm 1, \pm 2, \pm 3 \ldots
$$

Therefore, after performing the transform, the fault components due to rotor asymmetry appear exactly at transformed frequencies equal to their harmonic order $k$. Figs. 6(c) and 6(d) show the new representation of the time-frequency distribution after performing the rescaling of the frequency axis in accordance with (17). As expected, the mains component appears at the transformed frequency $f^{T}=0$ and the fault components appear at $f_{k r a}^{T}=k= \pm 1, \pm 2, \pm 3$. Hence, in a simple way, without any post-processing by maintenance staff, without speed measurement and regardless the working conditions, the fault components can clearly be distinguished among other frequencies.

Finally it is worth to note that although the method has been developed to diagnosis of rotor asymmetries, it is immediate adapt it to diagnose other kind of faults included in Table I. This would be achieved by simply changing the definition of the transformed frequency $f^{T}$, given by (17). For diagnosis of mixed eccentricity or bearing faults, the new expression of $f^{T}$ would be obtained by solving in $k$ the expressions of Table I corresponding to the specific fault, without no additional changes in the diagnosis scheme depicted in Fig. 1. Also, it is remarkable that once the conventional spectrogram is calculated, all the kind of faults can be analyzed quickly, by reorganizing the spectrogram through the suitable expression of the transformed frequency. This fact is relevant, since the generation of the spectrogram is the most costly process of 

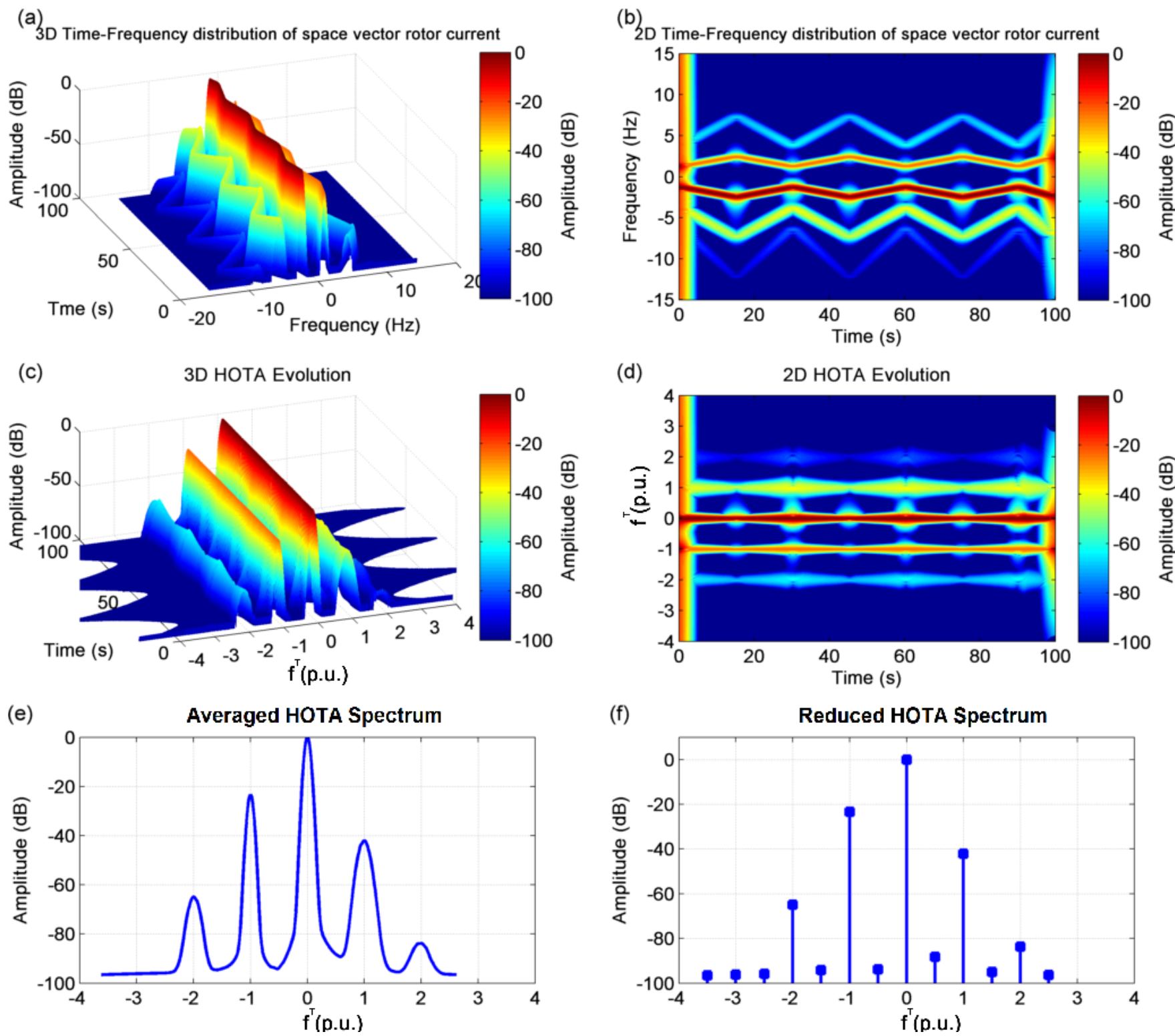

Fig. 6. Steps for HOTA of the simulated case of study. a) Time-frequency analysis of the simulated rotor current Park's vector amplitude (3D representation). b)Time-frequency analysis of the simulated rotor current Park's vector amplitude (2D representation). c) 3D HOTA spectrogram of the simulated rotor current Park's vector amplitude, obtained by re-scaling the frequency axis of (a) in accordance with (17). d) 2D representation of (c). e) Averaged HOTA spectrum. f) Reduced HOTA spectrum, where the $t-f$ distribution has been downsized to fifteen points.

the diagnosis method, and only needs to be performed once although different kind of faults have to be diagnosed.

\section{E. Summarizing information}

As proved in the previous paragraph, the transformedfrequency of each fault component remains constant regardless how operating conditions change. This fact makes possible to introduce a new sort of graph, shown in Fig. 6(e), similar to a steady-state spectrum, and designated as "Averaged HOTA Spectrum". It is built by plotting, for each transformed frequency, the mean value of its energy along the time of acquisition $T_{S}$ :

$$
\bar{E}\left(f^{T}\right)=\sum_{j=1}^{n} \frac{E\left(f_{j}^{T}\right)}{n}
$$

It is remarkable that for the integer transformed frequencies these mean values exactly match the average value of the energy of the corresponding fault components during the acquisition time; this fact makes the averaged HOTA Spectrum much more suitable than conventional spectrograms -such as of Fig . 6(b)- for characterizing the severity of the faults under non stationary conditions. Note also that they are obtained by simply summing the elements of each row of the HOTA spectrogram and dividing the sum by the number of elements of the row (n). Besides, an additional benefit is achieved going from a $3 \mathrm{D}$ representation to a $\mathrm{x}-\mathrm{y}$ graph, with the subsequent reduction of the amount of data to be stored, while keeping and even improving the reliability of the diagnostic. In the cases of simulation and experimental validation performed in this paper, the proposed technique has managed to reduce from 
$1,500,500$ to 10,000 the stored points at this step, that means a size 150 times lower than the original file.

However, it can still go further in reducing the sample size. From Fig. 6(e) it is clear that only the spectrum values with integer transformed frequencies $f^{T}=k= \pm 1, \pm 2, \pm 3 \ldots$ would be necessary to asses the machine condition. However, if only these values are stored, it could not be assured if these amplitudes are due to fault or are the result of leakage or spectral noise in the signal. Hence, it is advisable to keep several values of energy at intermediate positions, for enabling comparisons. From this reasoning, a new graph designated as "Reduced HOTA spectrum" (Fig. 6(f)) is introduced. It is a bar diagram plotting the averaged signal energy corresponding to the following transformed frequencies:

- At $f^{T}=k= \pm 1, \pm 2, \pm 3$. These bins give the average energy of the fault components.

- At $f^{T}=0$. This bin gives the average energy of the fundamental component.

- At $f^{T}= \pm 3.5, \pm 2.5, \pm 1.5, \pm 0.5$. These values, located at intermediate positions between the integer $\mathrm{k}$ orders allow to know the average value of spectral noise at these positions. These values, allow to resolve if the energy levels of the fault components correspond or not to a faulty condition.

This graph provides a reliable diagnosis information, which is not only easy to understand by the maintenance staff but also facilitates the use of automated systems of diagnosis avoiding the process of locating the fault components, which is extremely relevant in case of time-varying working conditions.

Besides, with only 15 points the reduced HOTA spectrum is much easier to integrate into predictive maintenance systems than conventional spectrograms, like that shown in Fig. 6(b) (with 1,500,500 points). Hence it simplifies the decision process while a data reduction over a ratio of 100,000 is achieved. It should be noted that this huge reduction is possible thanks to the proposed transform, which enables to know exactly the fault components locations, unlike conventional approaches, where the location of fault components is always undergone to uncertainty due to unavoidable errors in the speed measurement. This reduction is very relevant in wind turbines monitoring systems, because only the transmission of 15 data would be required instead of the original signal, drastically reducing the time and the bandwidth requirements. On the other hand, the capacity needed to perform the historical record of the machine condition is reduced, making easy the comparison of the current machine condition with previous conditions, thus enabling for an early detection of the machine damage.

\section{EXPERIMENTAL VALIDATION OF THE APPROACH}

The experimental validation has been performed using a $5 \mathrm{~kW}$ commercial WRIM working as a generator connected to the network, whose main characteristics are summarized in Appendix A. The WRIM rotor phase-resistances are affected by a slight constructive imbalance as shown in Table. III. Moreover, to test the sensitivity of the method, an additional resistance Rasym $=0.09 \Omega$ was connected in series to phase $R_{k}$, following the scheme shown in Fig. 2

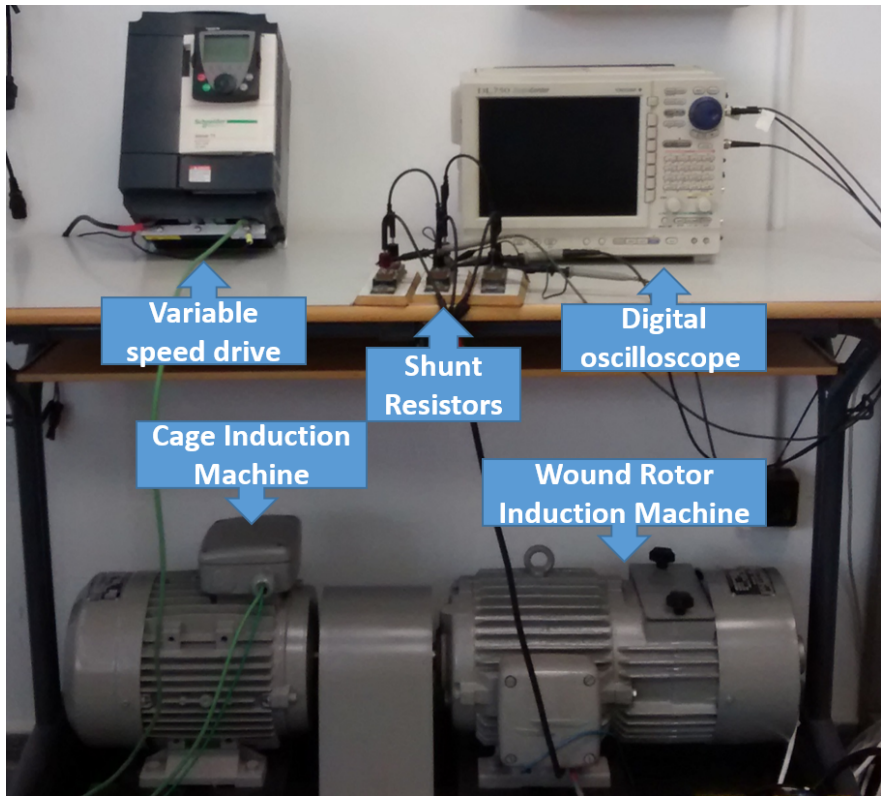

Fig. 7. Test bench used in the experimental validation.

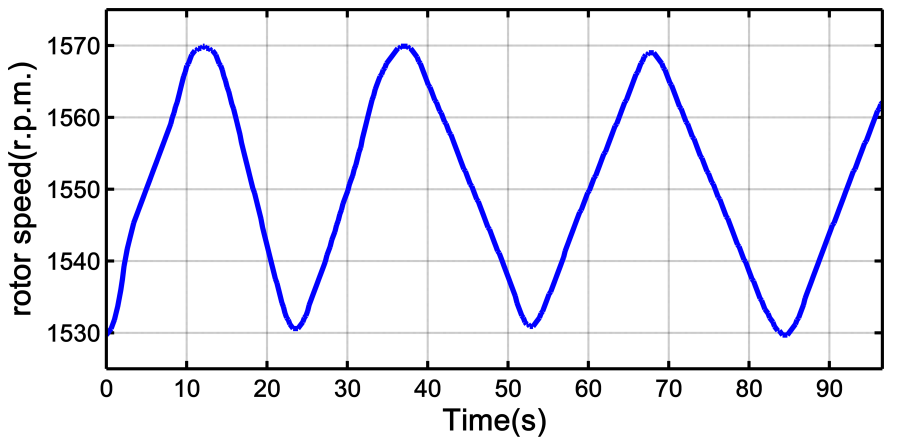

Fig. 8. Speed variation during the experimental validation.

In order to simulate the wind turbine, the WRIM has been directly coupled to a IM of $5 \mathrm{~kW}, 2$ pole pairs. The IM has been driven by a variable speed drive (VSD), making feasible the speed control of the group for simulating any changing wind regime. Fig. 8 shows the rotor speed variation along the tests in the experimental validation. Signals acquisition has been performed using a digital oscilloscope Yokogawa model SL100. The rotor currents have been acquired through shunt resistors using voltage sensors connected to an analogue input voltage module (ref. 701250, 10Ms, 12 bits) of the oscilloscope.

The results of the test are shown in Fig. 9. Figs. 9(a) and 9(b) depict the $t-f$ analysis of the measured Park's vector amplitude, in 3D and 2D respectively. These plots have been obtained through the Gabor transform, as explained in Section III-C. Although several components of the current can be clearly appreciated, it is difficult to decide if they are produced by a rotor asymmetry fault or by another cause, bearing in mind that no speed measurement was taken. The plots of Figs. 9(c) and 9(d) show the same time frequency distributions but after performing the rescaling procedure introduced in Section III-D. Now, the current components are located exactly on 
(a)

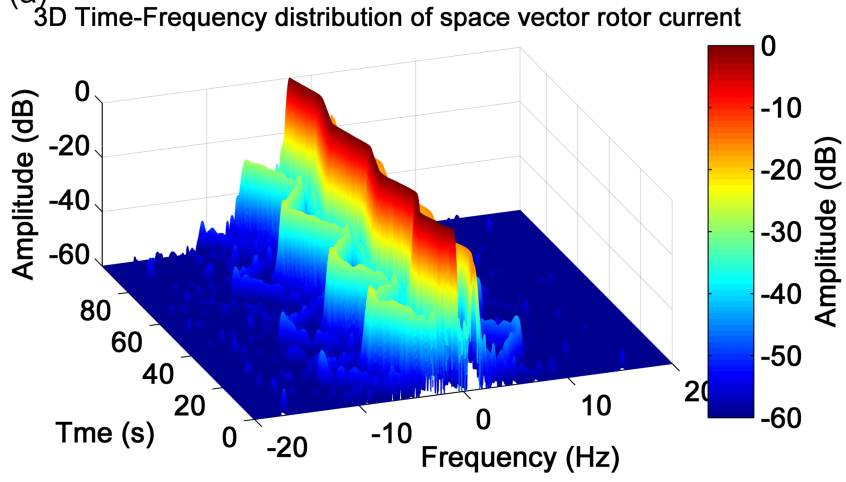

(c)

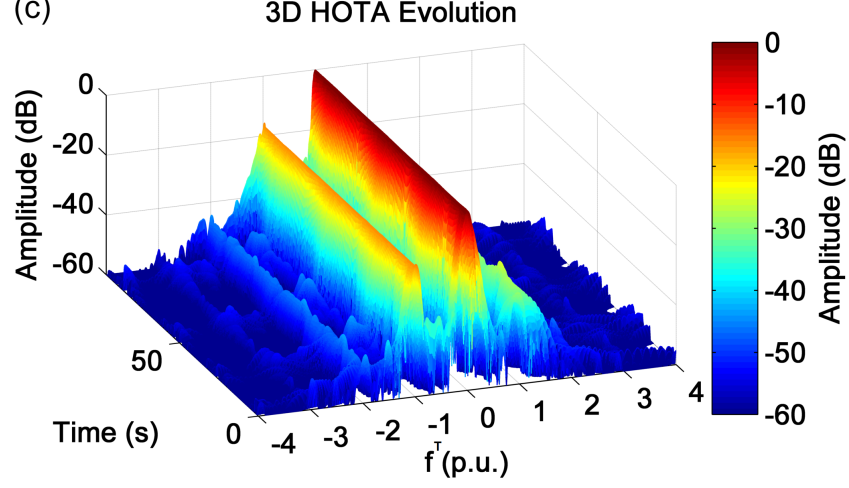

(e)

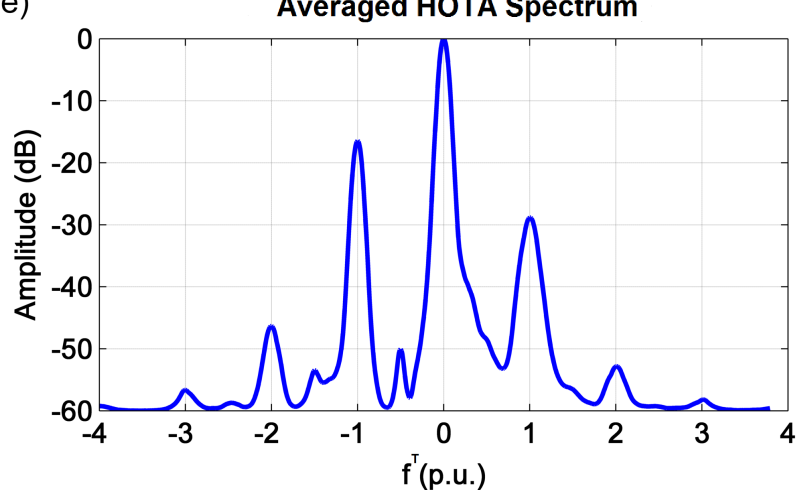

(b)

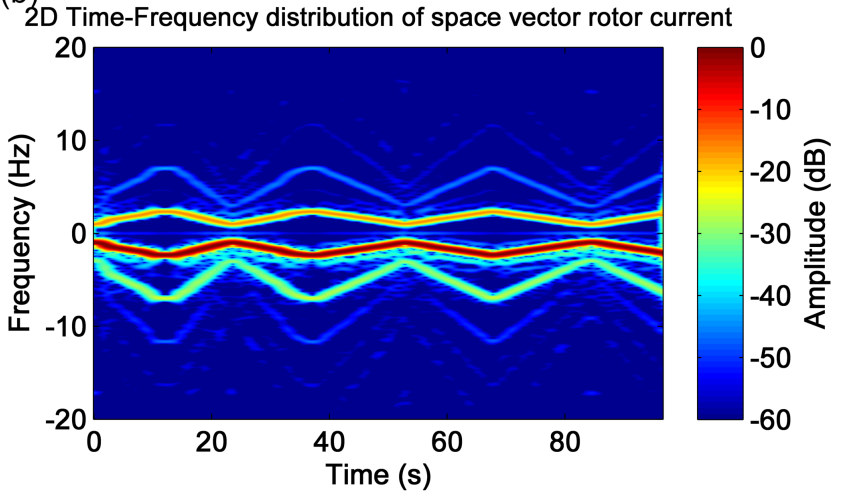

(d)

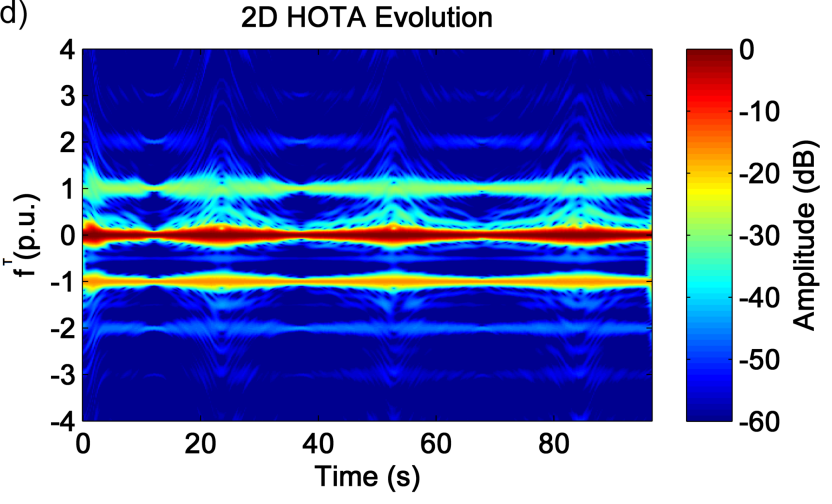

(f)

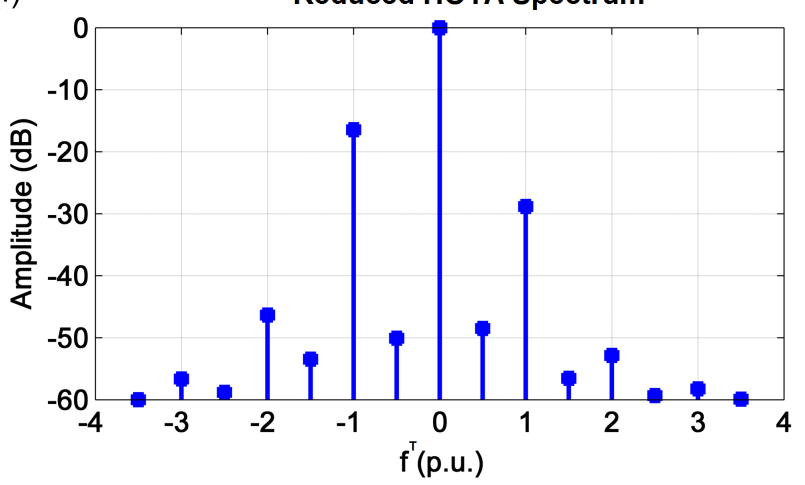

Fig. 9. Steps for HOTA of the experimental validation test. a) Time-frequency analysis of the tested rotor current Park's vector amplitude (3D representation). b)Time-frequency analysis of the tested rotor current Park's vector amplitude (2D representation). c) 3D HOTA spectrogram of the tested rotor current Park's vector amplitude, obtained by re-scaling the frequency axis of (a) in accordance with (17). d) 2D representation of (c). e) Averaged HOTA spectrum. f) Reduced HOTA spectrum, where the $t-f$ distribution has been downsized to fifteen points.

TABLE III

ROTOR RESISTANCES

\begin{tabular}{cccc}
\hline Phase & $\begin{array}{c}\text { Rotor resistance } \\
R_{k}(\Omega)\end{array}$ & $\begin{array}{c}\text { Additional resistance } \\
R_{\text {asym }}(\Omega)\end{array}$ & $\begin{array}{c}\text { Total resistance } \\
R_{k T}(\Omega)\end{array}$ \\
\hline $\mathrm{a}$ & 0.365 & 0.09 & 0.455 \\
$\mathrm{~b}$ & 0.333 & 0 & 0.333 \\
$\mathrm{c}$ & 0.333 & 0 & 0.333 \\
\hline
\end{tabular}

the transformed frequency axis at positions $f_{k r a}^{T}=k=$ $0, \pm 1, \pm 2, \pm 3$, demonstrating without any doubt that they are produced by a rotor asymmetry fault. It is remarkable that in the HOTA spectra, the left and right sideband not exchange their positions when the machine functions as a generator, contrary to what happens in conventional spectra, calculated in the frequency domain. This fact makes the HOTA spectra easier to understand than the conventional spectra.Finally, Figs. 9(e), and 9(f) summarize the information. Fig. 9(e) shows the averaged HOTA spectrum, that is, the plot of the averaged amplitudes across time for every transformed fre-quency $(10,000$ points instead of $1,500,500$ points used in Figs. 9(c) and 9(d)). Fig. 9(f) shows the reduced HOTA spectrum, introduced in Section III-E, where only 15 significant points of Fig. 9(e) are plotted. This kind of plot enables for a reliable diagnostic and at the same time for a substantial reduction of the system requirements for transferring and/or storing the information regarding the machine condition.

Comparing Figs. 6 and 9 it is remarkable the good agree- 
ment between simulated and experimental results, even though the simulation is carried out using a rather simplified model, which neglects saturation, space harmonics and slotting. The simulated currents only include the main component and the fault related components, which are located at the integer values of the harmonic order scale. This fact explains the small size of the fractional harmonic order (transformed frequency) components in the simulated spectra, since these values correspond to the floor noise of the spectrum.

\section{COMPaRATIVE ANALYSIS OF HeAlthy AND FAUlty MACHINES}

Fig. 10 compares the averaged HOTA spectrum and the reduced HOTA spectrum of the healthy generator with those obtained in the test of the faulty machine, in Section IV; the spectra of the healthy machine was obtained through a test in the same conditions than the faulty machine, using the speed profile depicted in Fig. 8. It is noticeable that the fault components appear located exactly at the same position in both cases, which is the main goal of the proposed approach. Besides, it can be seen how the amplitudes of the related fault components (with integer harmonic order) increase in the faulty machine, whereas the harmonics with not integer transformed frequency remains practically unchanged. Further, it can be seen a significant growth of the amplitude of the main fault components $\left(f^{T}=1, f^{T}=-1\right)$ in the faulty machine, which increase 22 and $18 \mathrm{~dB}$ respectively. Finally it is worth to comment that in the healthy machine spectra, the small fault components that appear at the transformed frequencies, are produced by the inherent constructive asymmetry of the rotor windings, shown in Table III.
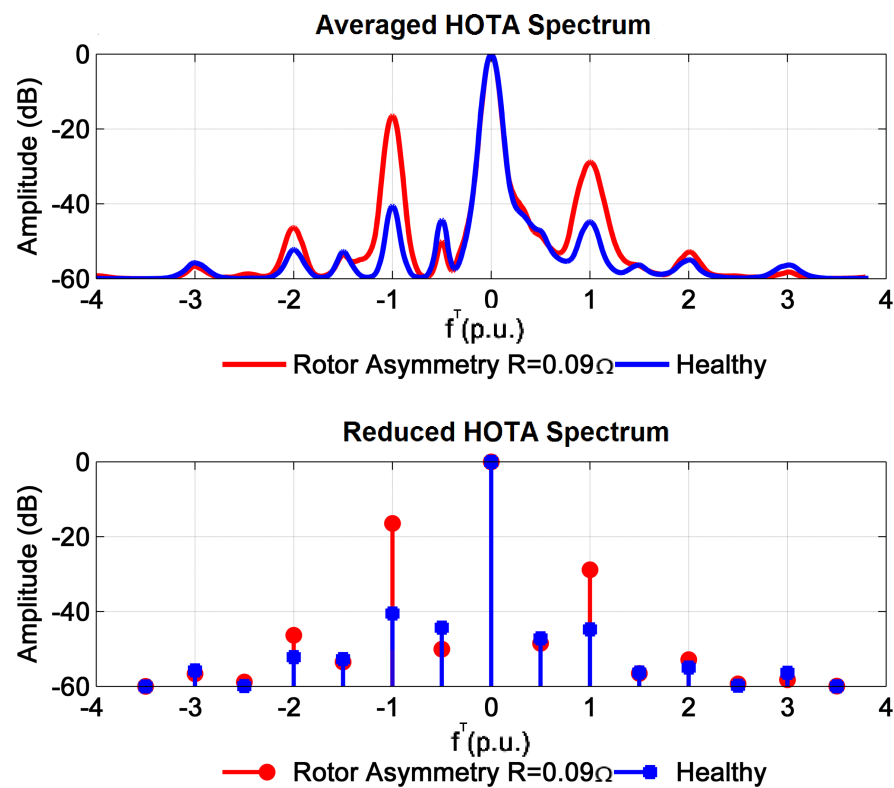

Fig. 10. Comparative study of differents levels of fault.

\section{CONCLUSIONS}

This paper introduces a novel approach for diagnosing rotor faults in WRIMs in stationary and non-stationary regimes. The proposed method is based on $t-f$ analysis and on the use of the harmonic order for tracking the fault related components. The proposed approach brings a triple achievement. First, no speed measurement is required for the diagnosis, avoiding the installation of speed sensors. Second, the method supplies the fault information in a very simple and comprehensive way, consisting on a plot similar to a conventional Fourier spectrum, but where the fault components are placed at fixed integer positions, the same for any speed or even if the machine works in non-stationary or transient regimes. And finally, the proposed method enables for a very compact representation of the diagnostic information, reducing greatly the number of data to be processed, transmitted or stored. This paper includes the description of the proposed method, its theoretical justification, and the simulation and experimental validation under timevarying conditions.

\section{APPENDIX A \\ WOUND ROTOR INDUCTION MACHINE}

Rated characteristics: $P=5 \mathrm{~kW}, U_{s}=230 / 400 \mathrm{~V}, U_{r}=233$ $\mathrm{V}, I=21.4 / 12.3 \mathrm{~A}, n=1430 \mathrm{rpm}, \cos \varphi=0.71, f=50 \mathrm{~Hz}, J$ $=0.2 \mathrm{Kgm}^{2}$

\section{REFERENCES}

[1] European Commission, "Secure, clean and efficient energy," Horizon 2020 Work Programme 20162017.

[2] J. Carroll, A. McDonald, and D. McMillan, "Failure rate, repair time and unscheduled O\&M cost analysis of offshore wind turbines," Wind Energy - Wiley Online Library, 2015.

[3] Z. Daneshi-Far, G. Capolino, and H. Henao, "Review of failures and condition monitoring in wind turbine generators," in Electrical Machines (ICEM), 2010 XIX International Conference on. IEEE, 2010, pp. 1-6.

[4] W. Liu, B. Tang, J. Han, X. Lu, N. Hu, and Z. He, "The structure healthy condition monitoring and fault diagnosis methods in wind turbines: A review," Renewable and Sustainable Energy Reviews, vol. 44, pp. 466472, 2015.

[5] X. Jin, W. Qiao, Y. Peng, F. Cheng, and L. Qu, "Quantitative Evaluation of Wind Turbine Faults Under Variable Operational Conditions," IEEE Transactions on Industry Applications, vol. 52, no. 3, pp. 2061-2069, May 2016.

[6] L. F. Villa, A. Reñones, J. R. Perán, and L. J. de Miguel, "Statistical fault diagnosis based on vibration analysis for gear test-bench under non-stationary conditions of speed and load," Mechanical Systems and Signal Processing, vol. 29, pp. 436-446, 2012.

[7] F. P. García Márquez, A. M. Tobias, J. M. Pinar Pérez, and M. Papaelias, "Condition monitoring of wind turbines: Techniques and methods," Renewable Energy, vol. 46, pp. 169-178, 2012.

[8] A. Bellini, F. Filippetti, C. Tassoni, and G.-A. Capolino, "Advances in Diagnostic Techniques for Induction Machines," IEEE Trans. Ind. Electron., vol. 55, no. 12, pp. 4109-4126, Dec 2008.

[9] H. Henao, G. A. Capolino, M. Fernandez-Cabanas, F. Filippetti, C. Bruzzese, E. Strangas, R. Pusca, J. Estima, M. Riera-Guasp, and S. Hedayati-Kia, "Trends in Fault Diagnosis for Electrical Machines: A Review of Diagnostic Techniques," IEEE Industrial Electronics Magazine, vol. 8, no. 2, pp. 31-42, June 2014.

[10] S. MA Cruz, AJ Marques Cardoso, "Rotor cage fault diagnosis in threephase induction motors by extended Park's vector approach," Electric Machines \&Power Systems, vol. 28, no. 4, pp. 289-299, 2000.

[11] S. H. Kia, H. Henao, and G. A. Capolino, "Diagnosis of Broken-Bar Fault in Induction Machines Using Discrete Wavelet Transform Without Slip Estimation," IEEE Transactions on Industry Applications, vol. 45, no. 4, pp. 1395-1404, July 2009.

[12] R. Puche-Panadero, M. Pineda-Sanchez, M. Riera-Guasp, J. RogerFolch, E. Hurtado-Perez, and J. Perez-Cruz, "Improved Resolution of the MCSA Method Via Hilbert Transform, Enabling the Diagnosis of Rotor Asymmetries at Very Low Slip," IEEE Transactions on Energy Conversion, vol. 24, no. 1, pp. 52-59, March 2009. 
[13] M. Riera-Guasp, M. Pineda-Sanchez, J. Perez-Cruz, R. Puche-Panadero, J. Roger-Folch, and J. A. Antonino-Daviu, "Diagnosis of Induction Motor Faults via Gabor Analysis of the Current in Transient Regime," IEEE Transactions on Instrumentation and Measurement, vol. 61, no. 6, pp. 1583-1596, June 2012.

[14] A. Ordaz-Moreno, R. de Jesus Romero-Troncoso, J. A. Vite-Frias, J. R. Rivera-Gillen, and A. Garcia-Perez, "Automatic Online Diagnosis Algorithm for Broken-Bar Detection on Induction Motors Based on Discrete Wavelet Transform for FPGA Implementation," IEEE Transactions on Industrial Electronics, vol. 55, no. 5, pp. 2193-2202, May 2008.

[15] J. Cusido, L. Romeral, J. A. Ortega, J. A. Rosero, and A. G. Espinosa, "Fault Detection in Induction Machines Using Power Spectral Density in Wavelet Decomposition," IEEE Transactions on Industrial Electronics, vol. 55, no. 2, pp. 633-643, Feb 2008.

[16] F. Briz, M. W. Degner, P. Garcia, and D. Bragado, "Broken Rotor Bar Detection in Line-Fed Induction Machines Using Complex Wavelet Analysis of Startup Transients," IEEE Transactions on Industry Applications, vol. 44, no. 3, pp. 760-768, May 2008.

[17] J. A. Rosero, L. Romeral, J. A. Ortega, and E. Rosero, "Short-Circuit Detection by Means of Empirical Mode Decomposition and WignerVille Distribution for PMSM Running Under Dynamic Condition," IEEE Transactions on Industrial Electronics, vol. 56, no. 11, pp. 4534-4547, Nov 2009.

[18] A. G. Espinosa, J. A. Rosero, J. Cusido, L. Romeral, and J. A. Ortega, "Fault Detection by Means of Hilbert-Huang Transform of the Stator Current in a PMSM With Demagnetization," IEEE Transactions on Energy Conversion, vol. 25, no. 2, pp. 312-318, June 2010.

[19] F. Vedreno-Santos, M. Riera-Guasp, H. Henao, M. Pineda-Sanchez, and R. Puche-Panadero, "Diagnosis of Rotor and Stator Asymmetries in Wound-Rotor Induction Machines Under Nonstationary Operation Through the Instantaneous Frequency," IEEE Trans. Ind. Electron., vol. 61, no. 9, pp. 4947-4959, Sept 2014.

[20] Y. Gritli, L. Zarri, C. Rossi, F. Filippetti, G. Capolino, and D. Casadei, "Advanced Diagnosis of Electrical Faults in Wound-Rotor Induction Machines," IEEE Trans. Ind. Electron., vol. 60, no. 9, pp. 4012-4024, Sept 2013

[21] A. Stefani, A. Yazidi, C. Rossi, F. Filippetti, D. Casadei, and G. Capolino, "Doubly Fed Induction Machines Diagnosis Based on Signature Analysis of Rotor Modulating Signals," Industry Applications, IEEE Transactions on, vol. 44, no. 6, pp. 1711-1721, Nov 2008.

[22] S. H. Kia, H. Henao, and G. Capolino, "Windings monitoring of wound rotor induction machines under fluctuating load conditions," in IECON 2011-37th Annual Conference on IEEE Industrial Electronics Society. IEEE, 2011, pp. 3459-3465.

[23] A. Sapena-Bano, M. Riera-Guasp, R. Puche-Panadero, J. MartinezRoman, J. Perez-Cruz, J. Roger-Folch, and M. Pineda-Sanchez, "Harmonic order tracking analysis: A speed-sensorless method for condition monitoring of wound rotor induction generators in wind turbines," in Diagnostics for Electrical Machines, Power Electronics and Drives (SDEMPED), 2015 IEEE 10th International Symposium on. IEEE, 2015, pp. 351-358.

[24] S. Djurovic, C. J. Crabtree, P. J. Tavner, and A. C. Smith, "Condition monitoring of wind turbine induction generators with rotor electrical asymmetry," IET Renewable Power Generation, vol. 6, no. 4, pp. 207216, July 2012.

[25] E. H. Bouchikhi, V. Choqueuse, M. E. H. Benbouzid, J. F. Charpentier, and G. Barakat, "A comparative study of time-frequency representations for fault detection in wind turbine," in IECON 2011 - 37th Annual Conference on IEEE Industrial Electronics Society, Nov 2011, pp. 35843589.

[26] A. Sapena-Bano, M. Pineda-Sanchez, R. Puche-Panadero, J. Perez-Cruz, J. Roger-Folch, M. Riera-Guasp, and J. Martinez-Roman, "Harmonic Order Tracking Analysis: A Novel Method for Fault Diagnosis in Induction Machines," Energy Conversion, IEEE Transactions on, vol. 30, no. 3, pp. 833-841, 2015.

[27] A. Bellini, F. Filippetti, G. Franceschini, C. Tassoni, and G. Kliman, "Quantitative Evaluation of Induction motor broken bars by means of electrical signature analysis," Industry Applications, IEEE Transactions on, vol. 37, no. 5, pp. 1248-1255, Sep 2001.

[28] J. Faiz and S. Moosavi, "Eccentricity fault detection-From induction machines to DFIG. -A review," Renewable and Sustainable Energy Reviews, vol. 55, pp. 169-179, 2016.

[29] B. R. Samaga and K. Vittal, "Comprehensive study of mixed eccentricity fault diagnosis in induction motors using signature analysis," International Journal of Electrical Power \& Energy Systems, vol. 35, no. 1, pp. $180-185,2012$.
[30] R. R. Schoen, T. G. Habetler, F. Kamran, and R. Bartfield, "Motor bearing damage detection using stator current monitoring," Industry Applications, IEEE Transactions on, vol. 31, no. 6, pp. 1274-1279, 1995.

[31] M. Mengoni, L. Zarri, Y. Gritli, A. Tani, F. Filippetti, and S. B. Lee, "Online Detection of High-Resistance Connections With NegativeSequence Regulators in Three-Phase Induction Motor Drives," Industry Applications, IEEE Transactions on, vol. 51, no. 2, pp. 1579-1586, 2015.

[32] M. Mengoni, L. Zarri, A. Tani, Y. Gritli, G. Serra, F. Filippetti, and D. Casadei, "Online Detection of High-Resistance Connections in Multiphase Induction Machines," Power Electronics, IEEE Transactions on, vol. 30, no. 8, pp. 4505-4513, 2015.

[33] R. H. Park, "Two-reaction theory of synchronous machines generalized method of analysis-part I," American Institute of Electrical Engineers, Transactions of the, vol. 48, no. 3, pp. 716-727, 1929.

[34] A. M. Cardoso and E. Saraiva, "Computer aided detection of airgap eccentricity in operating three-phase induction motors, by Park's vector approach," in Industry Applications Society Annual Meeting, 1991., Conference Record of the 1991 IEEE. IEEE, 1991, pp. 94-98.

[35] S. M. A. Cruz and A. J. M. Cardoso, "Stator winding Fault Diagnosis in three-phase synchronous and asynchronous motors, by the extended Park's vector approach," Industry Applications, IEEE Transactions on, vol. 37, no. 5, pp. 1227-1233, Sep 2001.

[36] H. Douglas, P. Pillay, and P. Barendse, "The detection of interturn stator faults in doubly-fed induction generators," in Industry Applications Conference, 2005. Fourtieth IAS Annual Meeting. Conference Record of the 2005, vol. 2. IEEE, 2005, pp. 1097-1102.

[37] P. Barendse, B. Herndler, M. Khan, and P. Pillay, "The application of wavelets for the detection of inter-turn faults in induction machines," in Electric Machines and Drives Conference, 2009. IEMDC'09. IEEE International. IEEE, 2009, pp. 1401-1407. 